\title{
DIAGNÓSTICO ECOGEOGRÁFICO DA OCORRÊNCIA DE JABUTICABEIRAS NATIVAS NO SUDOESTE DO PARANÁ ${ }^{1}$
}

\author{
MOESES ANDRIGO DANNER ${ }^{2}$, IDEMIR CITADIN ${ }^{3}$, \\ SIMONE APARECIDA ZOLET SASSO ${ }^{4}$, JULIO CAETANO TOMAZONI ${ }^{5}$
}

RESUMO - A jabuticabeira é uma fruteira nativa de ocorrência não generalizada na região sudoeste do Paraná, o que leva à hipótese de que esta espécie apresenta algumas preferências edafoclimáticas. Este trabalho teve como objetivo investigar as condições ecogeográficas e edafoclimáticas dos ambientes de ocorrência natural da jabuticabeira na região sudoeste do Paraná. O estudo foi efetuado em 14 sítios de ocorrência dessa espécie. Foram registradas 4.036 plantas adultas pertencentes à espécie Plinia cauliflora, em 201,9 ha de mata do Ecossistema Floresta com Araucária. Os sítios estão localizados predominantemente entre 650 e 850 $\mathrm{m}$ de altitude, e as plantas localizam-se sempre na parte mais alta da topossequência, local menos propenso à ocorrência de geadas. Jabuticabeiras que ocorrem em sítios de menor altitude e com maior temperatura média anual são maiores que aquelas em sítios de maior altitude e menor temperatura. Os solos onde ocorrem as jabuticabeiras são argilosos, fortemente ácidos (pH próximo a 4,0), com alto teor de matéria orgânica e ferro, alta saturação de alumínio, baixo teor de fósforo e muito baixo índice de saturação de bases.

Termos para indexação: Plinia cauliflora, Ecossistema Floresta com Araucária, recursos genéticos, erosão genética, conservação in situ.

\section{ECOGEOGRAFIC DIAGNOSIS OF THE OCCURRENCE OF WILD JABUTICABA TREES ON SOUTHWEST OF PARANA, BRAZIL}

\begin{abstract}
The jabuticaba tree is a native fruit specie of restrict occurrence in the southwest region of the state of Paraná, Brazil. This observation carried the hypothesis that jabuticaba trees have edafoclimatic preference. This study aimed to investigate the ecogeografic and edafoclimatic conditions of the sites of naturally occurrence of jabuticaba trees on southwest region of Parana, Brazil. The study was conducted at 14 sites of occurrence of jabuticaba tree. Were recorded 4,036 adult plants of the Plinia cauliflora specie, in 201.9 hectares in the Araucaria Forest Biome. The sites were located mostly between 650 and $850 \mathrm{~m}$ of altitude and the plants were located always in the highest part of the toposequence site with minus probability of frost. Jabuticaba trees that occur in sites with lower altitude and higher average annual temperature are bigger than others from occurrence in sites with higher altitude and lower temperature. The soils where the jabuticaba trees grow up were clayey, strongly acidic ( $\mathrm{pH}$ almost 4.0), with high content of organic matter and iron, aluminum high-saturation, low levels of phosphorus and very low saturation of bases.
\end{abstract}

Index terms - Plinia cauliflora, Araucaria Forest Biome, genetic resources, genetic loss, in situ conservation.

\footnotetext{
${ }^{1}$ (Trabalho 195-09). Recebido em: 18-08-2009. Aceito para publicação em: 13-05-2010.

${ }^{2}$ Eng. Agr., Doutorando UFPR, Bolsista CAPES. Professor Substituto, UTFPR, Campus Pato Branco. moesesandrigo@yahoo.com.br ${ }^{3}$ Eng. Agr., Dr., Professor Titular, UTFPR, Campus Pato Branco. Via do conhecimento, km 01, Pato Branco-PR. 85503-390. idemir@utfpr.edu.br

${ }^{4}$ Enga. Agra., MSc., UTFPR, Campus Pato Branco. iosasso@ibest.com.br

${ }^{5}$ Geógrafo, Dr., Professor UTFPR, Campus Francisco Beltrão.us Francisco Beltrão. caetano@utfpr.edu.br
} 


\section{INTRODUÇÃO}

A jabuticabeira (Plinia sp.) pertence à família Myrtaceae e é endêmica do Centro-Sul/Sudeste do Brasil (MATTOS, 1983). A produção comercial dessa fruteira é pequena e limitada a determinadas regiões de ocorrência natural. Porém, seu potencial de cultivo e comercialização é grande, em função das características organolépticas dos frutos (BARROS et al., 1996) e porque pode despertar o interesse da indústria farmacêutica e alimentícia, pois contém alto teor de óleos essenciais nas folhas (APEL et al., 2006) e antocianinas na casca do fruto (TEIXEIRA et al., 2008). Seu uso como planta ornamental também é indicado (DEMATTÊ, 1997). A jabuticabeira já está sendo testada em cultivos na Flórida, EUA, e em países das Américas Central e do Sul (BALERDI et al., 2006). Mesmo apresentando todo esse potencial, pouca pesquisa tem sido feita com esta fruteira.

$\mathrm{Na}$ região sudoeste do Paraná, existem remanescentes florestais do Ecossistema Floresta com Araucária em que há a ocorrência natural da jabuticabeira, da espécie Plinia cauliflora. Essas matas já foram submetidas à intervenção humana e atualmente são mantidas como áreas de reserva legal de propriedades particulares. Nesses locais, durante a maturação da jabuticaba, a colheita é realizada de forma extrativista, e sua comercialização in natura ocorre às margens de rodovias da região, tornandose atividade de importância econômica e social para famílias carentes.

A conservação dos recursos genéticos dessa espécie, seja in situ ou ex situ, é parte fundamental nas estratégias de desenvolver o melhoramento genético e aumentar a exploração dessa fruteira em cultivos comerciais. Nesse sentido, inicialmente, é necessária a caracterização ecogeográfica e edafoclimática dos ambientes de ocorrência dessa espécie, de forma a fornecer indicativos do número de indivíduos, de sua localização e das condições ambientais em que as plantas se desenvolvem (ROMAGNOLO; SOUZA, 2006; LORENZINI et al., 2007; MESQUITA et al., 2007; NASCIMENTO et al., 2007).

O objetivo deste trabalho foi investigar as condições ecogeográficas e edafoclimáticas dos ambientes de ocorrência natural da jabuticabeira na região sudoeste do Paraná.

\section{MATERIAL E MÉTODOS}

Utilizando aparelho de GPS (Global Position System), com precisão média de $12 \mathrm{~m}$, foi realizado o mapeamento de 14 remanescentes florestais contendo plantas nativas de jabuticabeira, na região sudoeste do Paraná, de abril de 2007 a junho de 2008. Esses locais foram denominados sítios de ocorrência, e sua escolha e localização foram feitas com base em informações de agricultores e agentes da Extensão Rural (EMATER/PR).

A partir dos dados da posição geográfica coletados nos sítios de ocorrência (latitude, longitude e altitude), efetuou-se a confecção de cartas da dispersão geográfica da jabuticabeira na região sudoeste do Paraná.

Para a elaboração das cartas, utilizouse o Sistema de Informações Geográficas (SIG) SPRING (INPE, 2008). Em ambiente SPRING, criou-se o banco de dados, seguido do projeto, no qual se definiu o retângulo envolvente da área a ser trabalhada. Na sequência, foi criada uma série de categorias (temáticas e de imagens) e planos de informação, para, então, possibilitar a inserção dos dados.

Primeiramente, efetuou-se a confecção do mapa político, com base em mapa disponibilizado pelo Ipardes (2002), localizando os pontos referentes aos sítios de ocorrência de jabuticabeira, de acordo com as divisas municipais da região em estudo.

$\mathrm{Na}$ sequência, utilizaram-se as cartas climáticas extraídas de Iapar (2003), para a classificação da hipsometria e da temperatura média anual, e elaboraram-se cartas através da inserção dos pontos, referentes aos sítios de ocorrência de jabuticabeira, sobre as referidas cartas climáticas na região sudoeste do Paraná.

Juntamente com o trabalho de mapeamento, realizou-se a contagem do número de plantas nativas de jabuticabeira existentes nos sítios de ocorrência, para obter a densidade de plantas nas áreas mapeadas, assim como a medição da altura e do diâmetro à altura do peito (DAP) de plantas, em cada sítio de ocorrência. A altura das plantas foi estimada por observação óptica com ipsômetro, e o DAP, calculado a partir da medição da circunferência (perímetro) das plantas com fita métrica. Realizaram-se coleta, análise química e granulométrica dos solos $(0-20$ $\mathrm{cm}$ ) em cada sítio de ocorrência. Os dados de cada parâmetro de solo dos 14 sítios foram apresentados conjuntamente por estatística descritiva (média e desvio-padrão) e interpretados segundo a Comissão... (2004). Procedeu-se também à observação visual de espécies arbóreas de maior ocorrência nas matas, juntamente com a jabuticabeira. A identificação das espécies foi baseada em Lorenzi (2002).

Os dados de altura e DAP de plantas de cada sítio de ocorrência foram submetidos à análise de variância, em delineamento inteiramente casualizado, com 10 repetições (plantas nativas de jabuticabeira), 
e teste de Scott-Knott $(P \leq 0,05)$, utilizando o programa computacional Genes (CRUZ, 2006). Procedeu-se também ao estudo das correlações de Pearson entre as médias de altitude com altura e DAP de plantas, verificando-se a significância, pelo teste $\mathrm{t}(P \leq 0,01)$.

\section{RESULTADOS E DISCUSSÃO}

Observou-se que, no sudoeste do Paraná, a ocorrência natural de jabuticabeiras limita-se a poucos sítios florestais remanescentes do Ecossistema Floresta com Araucária.

Nos 14 sítios de ocorrência mapeados, foram registradas 4.036 plantas adultas, pertencentes à espécie Plinia cauliflora, conforme descrição botânica de Mattos (1983), numa área de 201,9 ha (Tabela 1). Os sítios de ocorrência estão distribuídos em sete municípios da região sudoeste do Paraná, sendo seis em Pato Branco (Figura 1).

Os exemplares adultos de jabuticabeira estavam localizados entre $577 \mathrm{~m}$ (Marcolina - Coronel Vivida) e 989 m de altitude (Bortoli - Clevelândia). A maior frequência foi observada nas altitudes entre 650 e $850 \mathrm{~m}$ (Figura 2). Segundo Lorenzini et al. (2007), a goiabeira serrana (Acca sellowiana), também da família Myrtaceae, é uma planta de altitudes elevadas, ocorrendo com maior frequência entre 900 e 1.300 m, no Planalto Serrano Catarinense. Isso é indicativo de que a ocorrência predominante de algumas espécies vegetais pode ser determinada pela altitude e sua interação com o ambiente.

Observou-se, em todos os sítios de ocorrência, que a jabuticabeira não apresenta distribuição generalizada, mas localiza-se na parte mais alta da topossequência, nunca em áreas de baixada. Além disso, as plantas não ocorrem de forma dispersa, mas, sim, em agrupamentos, provavelmente formados por indivíduos aparentados.

O sítio Fazenda Jaboticabal (Chopinzinho) é o que contém maior número de plantas dentre todos (1.400 plantas) e apresenta uma das maiores densidades $\left(59,6\right.$ plantas ha $\left.^{-1}\right)$. Nesse local, observou-se que a área de mata $(23,5 \mathrm{ha})$ foi mantida devido à ocorrência da jabuticabeira, sendo aproveitada como reserva legal obrigatória da propriedade. Esse fato também foi observado nos sítios Klein e Bortoli (Clevelândia), Marcolina (Coronel Vivida) e José Silva (Vitorino). No sítio Pisca (Pato Branco), observou-se que a pequena área de remanescente da mata original (1,6 ha) foi mantida somente na parte alta do terreno onde estão as jabuticabeiras, o que proporcionou alta densidade de plantas (40,6 plantas $h^{-1}{ }^{-1}$. Essa mesma explicação aplica-se às propriedades Russo e Independência (Pato Branco). Nesses sítios, o ambiente natural foi altamente modificado pela retirada de plantas e pela criação de gado no seu interior, fato que tem restringido a regeneração natural dessa fruteira e de outras espécies nativas. No caso do sítio Iapar (Pato Branco), que pertence ao poder público, a área de mata nativa mantida é referente a toda a reserva legal da propriedade. Em seu interior, ocorrem plantas de jabuticabeira apenas em cinco agrupamentos. Como a área de reserva legal é a maior e menos alterada dentre todos os sítios (78,3 ha), a densidade de plantas de jabuticabeira é baixa $\left(0,7\right.$ plantas ha $\left.{ }^{-1}\right)$.

De forma geral, a altura das plantas foi relacionada à altitude dos sítios de ocorrência. A média de altura de plantas variou de 12,5 a 19,3 m e foi maior nos sítios Marcolina (Coronel Vivida) e Mattei (Nova Esperança do Sudoeste). Observou-se que esses sítios estão localizados em menor altitude $(<650 \mathrm{~m})$ e apresentam maior temperatura média anual, $19-20^{\circ} \mathrm{C}$ (Figura 3). Além disso, nos sítios Klein e Bortoli (Clevelândia), localizados em maior altitude (acima de $900 \mathrm{~m}$ ) e com menor temperatura média anual $\left(17-18^{\circ} \mathrm{C}\right)$, as plantas apresentaram menor altura, embora sem diferir dos sítios Pícolo e Iapar. Verificou-se correlação negativa entre a altura média de plantas dos diferentes sítios com relação à altitude $\left(r=-0,70^{* *}\right)$. Porém, o DAP das plantas de jabuticabeira não foi correlacionado com a altitude $\left(r=-0,25^{\mathrm{NS}}\right)$. Segundo Danner et al. (2008), a diferença de altitude e temperatura média anual pode interferir, também, na qualidade de frutos de jabuticabeira entre os diferentes sítios de ocorrência da região sudoeste do Paraná.

Também se pode inferir que a dispersão natural das plantas, provavelmente, não sofreu influência antrópica no passado, devido à recente colonização da região sudoeste do Paraná (a partir de 1940). Isso porque, acredita-se, as plantas adultas de jabuticabeira provavelmente têm idade superior a 70 anos, pois há informações generalizadas de que, quando os colonizadores chegaram à região, as jabuticabeiras já eram encontradas no interior das matas. Por outro lado, durante o processo de colonização da região, houve a ação antrópica na manutenção ou exclusão de áreas de mata com jabuticabeiras. Por isso, os sítios remanescentes contendo jabuticabeiras sofreram efeito do interesse do homem na manutenção dessa fruteira e/ou da mata onde ela está localizada.

Além da araucária (Araucaria angustifolia (Bert.) O. Kuntze), observaram-se várias espécies arbóreas que ocorrem associadas à jabuticabeira no sudoeste do Paraná. Dentre elas, as principais foram canelas (Cryptocarya sp., Nectandra sp., Ocotea sp.), grápia (Apuleia leiocarpa (Vog.) Macgr.), ce- 
dro (Cedrela fissilis Vell.), vassourão (Piptocarpha angustifolia Duséss.), maria-preta (Diatenopteryx sorbifolia Radlk.), tarumã (Vitex montevidensis Cham.), jerivá (Syagrus romanzoffiana (Cham.) Glassm.), sapopema (Slonea monosperma Vell.) e outras fruteiras da família Myrtaceae, como cerejeira-do-mato (Eugenia involucrata DC.), uvalheira (Eugenia pyriformis Cambess.), guabirobeira (Campomanesia xantocarpa O. Berg), guabijuzeiro (Myrcianthes pungens), cambuí (Myrciaria tenella (DC.) O. Berg) e sete-capote (Campomanesia guazumifolia (Cambess.) O. Berg).

Considerando a média das análises químicas e granulométricas dos solos dos sítios de ocorrência, observaram-se como principais características o alto teor de matéria orgânica (M.O.), baixo teor de fósforo, baixo a médio teor de cálcio, médio a alto teor de potássio e magnésio, alto teor de micronutrientes, especialmente ferro e manganês, média a baixa soma de bases (SB) e muito baixo índice de saturação de bases (V\%). Além disso, os solos são argilosos, com teor acima de $50 \%$ de argila, fortemente ácidos ( $\mathrm{pH}$ próximo a 4,0) e com alta saturação de alumínio (Tabela 2). Essas características são devidas aos minerais originais constituintes desses solos, principalmente micas e feldspatos, os quais estão em estado altamente intemperizados e nos quais as bases trocáveis já foram altamente lixiviadas.

Onde ocorrem as jabuticabeiras na região sudoeste do Paraná, no alto da topossequência, os solos são classificados como Latossolos Vermelhos distroférricos, tendo predomínio de caulinita como tipo de argila, a qual é predominantemente constituída de óxidos de ferro e de alumínio (EMBRAPA, 1999). Mesquita et al. (2007) observaram as condições de ocorrência natural do araticum (Anona crassiflora Mart.) em áreas do cerrado de Goiás e verificaram que a espécie ocorre em alta densidade em Latossolos não concrecionários dos chapadões, com baixo teor de matéria orgânica e baixa concentração de ferro, o que difere do verificado para jabuticabeira neste trabalho.

Observou-se também que a regeneração natural da jabuticabeira está comprometida nos sítios de ocorrência mapeados, havendo grande risco de erosão genética das plantas remanescentes, visto que foi observado baixo número de plantas jovens nas matas. As ameaças mais comuns à regeneração são a entrada e/ou permanência de animais de criação e as roçadas anuais feitas sob a copa das plantas. Além disso, em alguns casos, há a proximidade com a área urbana e/ou rodovias, nas quais ocorrem intensa invasão e colheita da grande maioria dos frutos, durante a sua maturação. Nesse âmbito, é importante que os sítios de ocorrência sejam incluídos no SISLEG (Sistema de Manutenção, Recuperação e Proteção da Reserva Florestal Legal e Áreas de Preservação Permanente), seguindo o Decreto estadual n 387/99 (PARANÁ, 2008), para que os proprietários intensifiquem os cuidados na regeneração da mata. Isso deverá contribuir para a conservação in situ dos recursos genéticos de jabuticabeira na região sudoeste do Paraná, assim como para a regeneração natural da espécie.

Esse diagnóstico deve contribuir para o entendimento das condições ecogeográficas e edafoclimáticas do habitat de ocorrência da jabuticabeira $\mathrm{e}$ servir como base do manejo em cultivos comerciais de Plinia cauliflora. Por exemplo, indica que a espécie tolera solos fortemente ácidos e com alta saturação de alumínio. A localização dos sítios e a contagem das plantas devem contribuir também para elaborar estratégias de conservação in situ e ex situ do germoplasma da espécie, o que é importante, pois as suas sementes são recalcitrantes (VALIO; FERREIRA, 1992), o que impossibilita a formação de um banco de sementes para conservar a variabilidade. 
TABELA 1 - Caracterização ecogeográfica dos sítios de ocorrência de plantas nativas de jabuticabeira (Plinia cauliflora) na região sudoeste do Paraná. UTFPR, Câmpus Pato Branco, 2009.

\begin{tabular}{lcccccc}
\hline \multicolumn{1}{c}{$\begin{array}{c}\text { Sítio de ocorrência } \\
\text { (Nomenclatura/Localização) }\end{array}$} & $\begin{array}{c}\text { Altitude } \\
\text { Média (m) }\end{array}$ & $\begin{array}{c}\text { Área } \\
\text { (ha) }\end{array}$ & $\begin{array}{c}\mathrm{N}^{\mathrm{o}} \text { de } \\
\text { plantas }\end{array}$ & $\begin{array}{c}\text { Densidade } \\
\text { (plantas/ha) }\end{array}$ & $\begin{array}{c}\text { Altura } \\
(\mathrm{m})\end{array}$ & $\begin{array}{c}\text { DAP } \\
(\mathrm{m})\end{array}$ \\
\hline Tesser - Vitorino & 814 & 12,0 & 100 & 8,3 & $14,7 \mathrm{c}$ & $0,38 \mathrm{c}$ \\
Russo - Pato Branco & 710 & 2,8 & 130 & 46,4 & $14,9 \mathrm{c}$ & $0,41 \mathrm{c}$ \\
Pícolo - Pato Branco & 778 & 7,5 & 65 & 8,7 & $12,6 \mathrm{~d}$ & $0,45 \mathrm{~b}$ \\
Pisca - Pato Branco & 675 & 1,6 & 65 & 40,6 & $14,2 \mathrm{c}$ & $0,36 \mathrm{c}$ \\
Pagnoncelli - Mariópolis & 824 & 10,8 & 165 & 15,3 & $15,9 \mathrm{~b}$ & $0,40 \mathrm{c}$ \\
Mattei - Nova Esperança do Sudoeste & 648 & 10,0 & 115 & 11,5 & $18,0 \mathrm{a}$ & $0,51 \mathrm{a}$ \\
Faz. Jaboticabal - Chopinzinho & 854 & 23,5 & 1.400 & 59,6 & $14,9 \mathrm{c}$ & $0,54 \mathrm{a}$ \\
Marcolina - Coronel Vivida & 577 & 4,9 & 320 & 65,3 & $19,3 \mathrm{a}$ & $0,45 \mathrm{~b}$ \\
Klein - Clevelândia & 963 & 12,3 & 930 & 75,6 & $12,9 \mathrm{~d}$ & $0,32 \mathrm{c}$ \\
José Silva - Vitorino & 820 & 2,4 & 110 & 45,8 & $14,7 \mathrm{c}$ & $0,45 \mathrm{~b}$ \\
Iolanda Pelozzo - Pato Branco & 739 & 26,1 & 115 & 4,4 & $14,8 \mathrm{c}$ & $0,34 \mathrm{c}$ \\
Independência - Pato Branco & 730 & 3,6 & 70 & 19,4 & $16,4 \mathrm{~b}$ & $0,39 \mathrm{c}$ \\
IAPAR - Pato Branco & 717 & 78,3 & 55 & 0,7 & $13,5 \mathrm{~d}$ & $0,33 \mathrm{c}$ \\
Bortoli - Clevelândia & 989 & 6,1 & 396 & 64,9 & $12,5 \mathrm{~d}$ & $0,36 \mathrm{c}$ \\
\hline Média & 774 & 14,4 & 288 & 20,0 & 15,0 & 0,41 \\
\hline CV (\%) & & & & & 11,5 & 18,9 \\
\hline Total & & & & & & \\
\hline
\end{tabular}

Médias seguidas de letras distintas diferem entre si, pelo teste de Scott-Knott $(P \leq 0,05)$. DAP: diâmetro à altura do peito.

TABELA 2 - Fertilidade natural e granulometria dos solos (camada 0-20 cm) de remanescentes florestais com ocorrência natural de jabuticabeira (Plinia cauliflora), na região sudoeste do Paraná UTFPR, Câmpus Pato Branco, 2009.

\begin{tabular}{cccccc}
\hline $\mathrm{pH}\left(\mathrm{CaCl}_{2}\right)$ & $\mathrm{Al}$ & $\mathrm{K}$ & $\begin{array}{c}\mathrm{Ca} \\
\mathrm{cmol}_{\mathrm{c}} \mathrm{dm}^{-3}\end{array}$ & $\mathrm{Mg}$ & $\mathrm{SB}$ \\
\cline { 2 - 5 } $4,04 \pm 0,5$ & $2,36 \pm 1,1$ & $0,27 \pm 0,1$ & $1,78 \pm 1,9$ & $1,57 \pm 0,9$ & $3,61 \pm 2,7$ \\
\hline $\mathrm{P}$ & $\mathrm{Cu}$ & $\mathrm{Fe}$ & $\mathrm{Zn}$ & $\mathrm{Mn}$ & M.O. (\%) \\
& & $\mathrm{mg} \mathrm{dm}^{-3}$ & & & \\
\cline { 2 - 5 } $3,28 \pm 2,1$ & $5,36 \pm 3,1$ & $65,07 \pm 32,4$ & $4,55 \pm 2,5$ & $109,30 \pm 44,4$ & $6,56 \pm 1,0$ \\
\hline $\mathrm{V}(\%)$ & Sat. Al. (\%) & $\mathrm{CTC}$ & Argila (\%) & Areia (\%) & Silte (\%) \\
$21,81 \pm 18,6$ & $44,37 \pm 21,5$ & $17,53 \pm 2,2$ & $59,3 \pm 6,8$ & $10,3 \pm 6,0$ & $30,4 \pm 10,5$ \\
\hline
\end{tabular}

Os dados são valores médios acompanhados pelo desvio-padrão de 14 remanescentes florestais de mata com araucária, com ocorrência natural de jabuticabeira. 


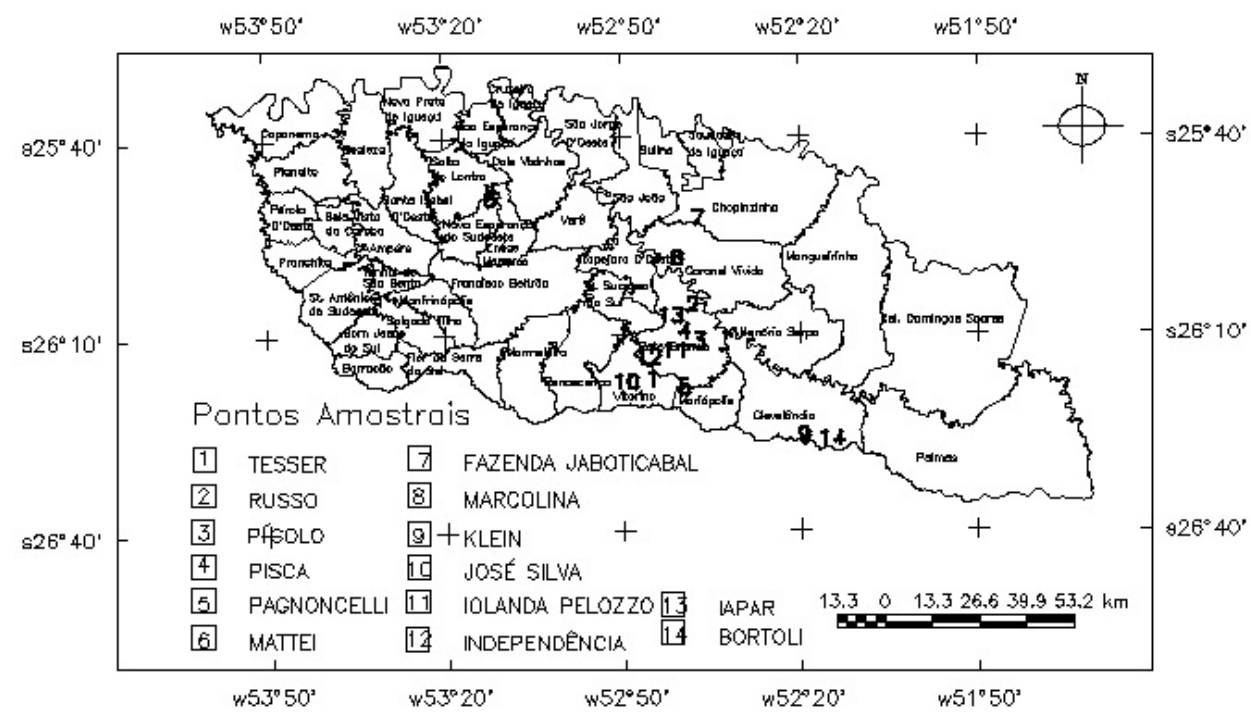

FIGURA 1 - Mapa político da região sudoeste do Paraná, com pontos representando os 14 sítios de ocorrência de jabuticabeira (Plinia cauliflora). UTFPR, Câmpus Pato Branco, 2009. Fonte do mapa-base: Ipardes (2002).

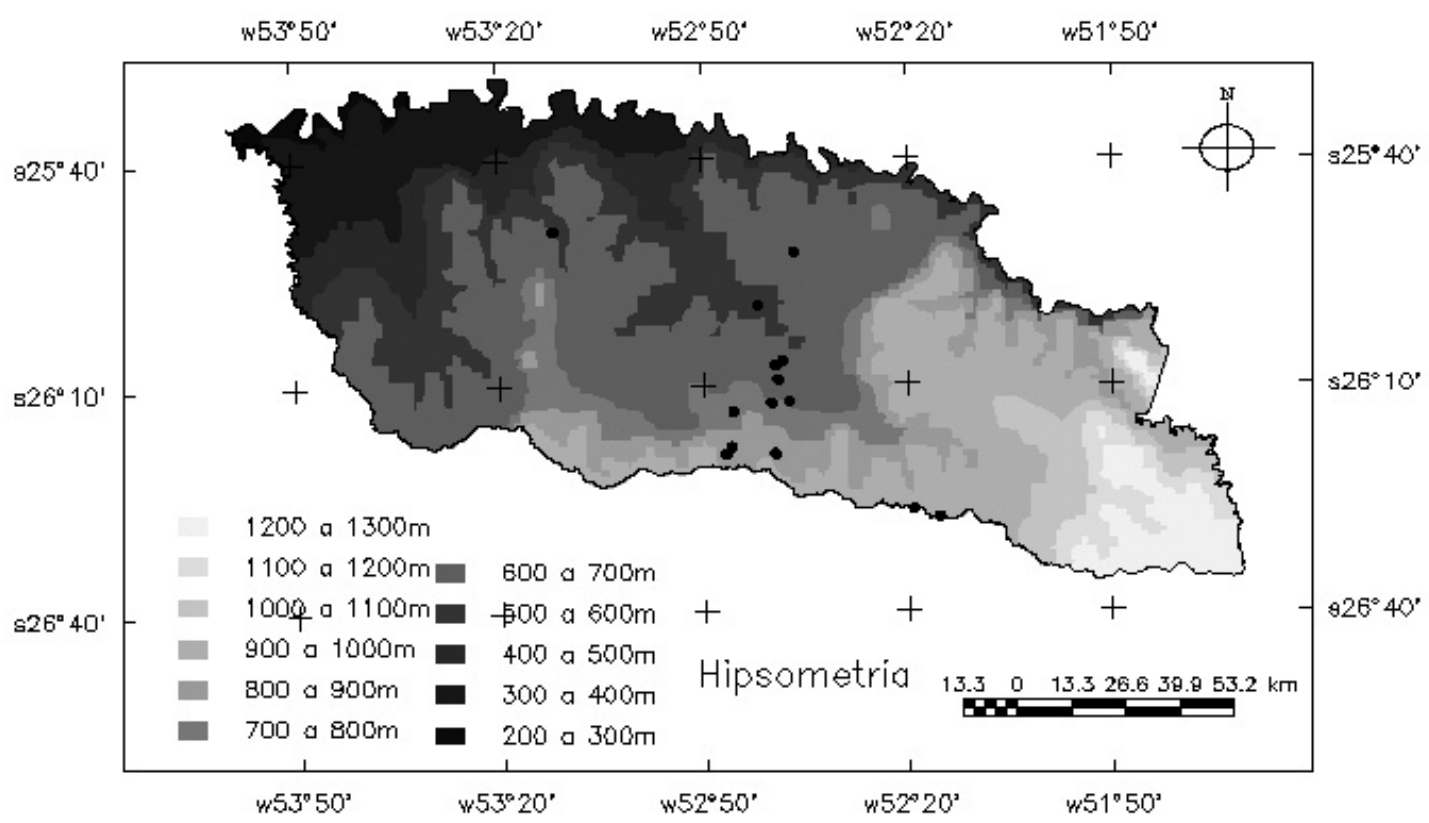

FIGURA 2 - Mapa da hipsometria (altitude, m) da região sudoeste do Paraná, com pontos representando os 14 sítios de ocorrência de jabuticabeira (Plinia cauliflora). UTFPR, Câmpus Pato Branco, 2009. Fonte do mapa-base: Iapar (2003). 


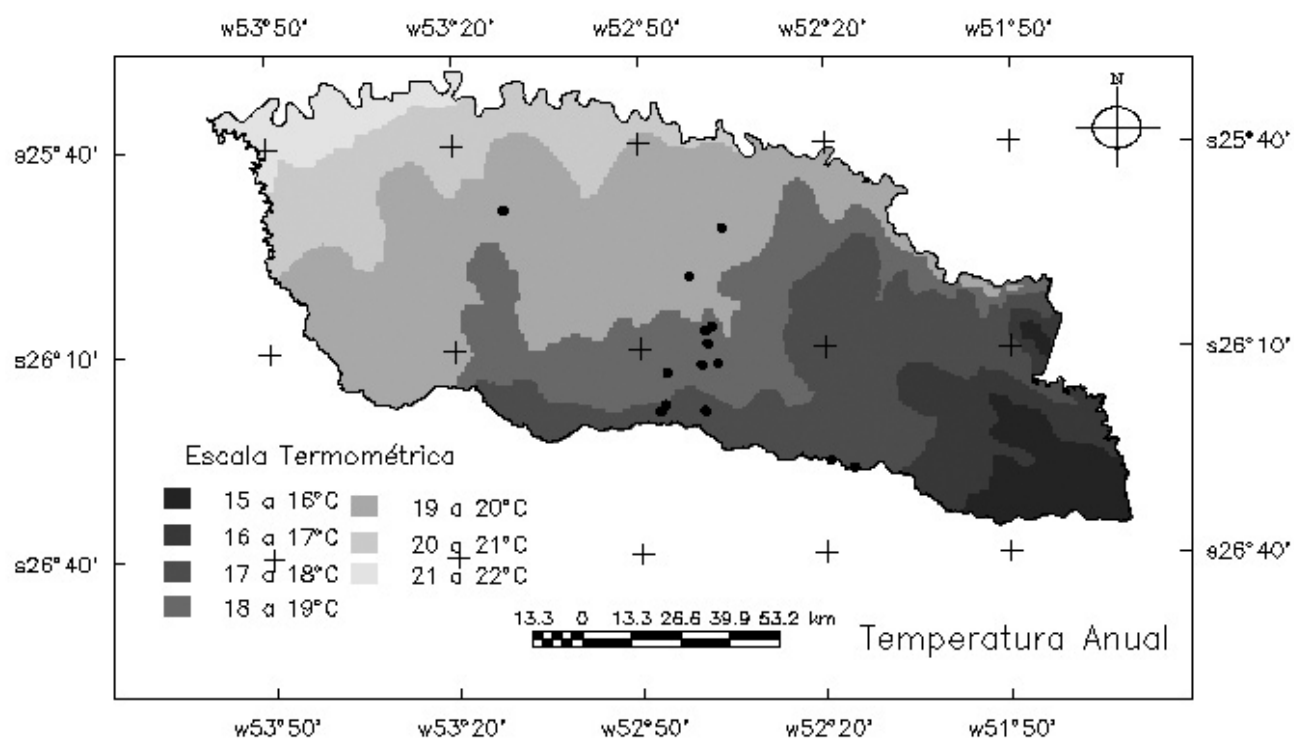

FIGURA 3 - Mapa da temperatura média anual $\left({ }^{\circ} \mathrm{C}\right)$ da região sudoeste do Paraná, com pontos representando os 14 sítios de ocorrência de jabuticabeira (Plinia cauliflora). UTFPR, Câmpus Pato Branco, 2009. Fonte do mapa-base: Iapar (2003).

\section{CONCLUSÕES}

1-Na região sudoeste do Paraná, os sítios de ocorrência de jabuticabeira (Plinia cauliflora) mapeados estão localizados entre 577 a 989 m de altitude, sempre na parte mais alta da topossequência.

2-Jabuticabeiras que ocorrem nos sítios de menor altitude e com maior temperatura média anual são mais altas que aquelas de sítios de maior altitude e menor temperatura.

3-Os solos dos sítios de ocorrência de jabuticabeira são argilosos, fortemente ácidos $(\mathrm{pH}$ próximo a 4,0), com alto teor de matéria orgânica e ferro, alta saturação de alumínio, baixo teor de fósforo e muito baixo índice de saturação de bases.

\section{REFERÊNCIAS}

APEL, M.A.; SOBRAL, M.; ZUANAZZI, J.A.; HENRIQUES, A.T. Essential oil composition of four Plinia species (Myrtaceae). Flavour and Fragrance Journal, Chichester, v.21, p.565-567, 2006.

BALERDI, C.F.; RAFIE, R.; CRANE, J. Jaboticaba (Myrciaria cauliflora, Berg.): a delicious fruit with an excellent market potential. Proceedings of the Florida State Horticultural Society, Gainesville, v.119, p.66-68, 2006.

BARROS, R.S.; FINGER, F.L.; MAGALHÃES, M.M. Changes in nonstructural carbohydrates in developing fruit of Myrciaria jaboticaba. Scientia Horticulturae, Amsterdam, v.66, p.209-215, 1996.

COMISSÃO DE QUÍMICA E FERTILIDADE DO SOLO. Manual de adubação e calagem para os Estados do Rio Grande do Sul e de Santa Catarina. 10. ed. Porto Alegre: Sociedade Brasileira de Ciência do Solo, Núcleo Regional Sul/UFRGS, 2004. 400p.

CRUZ, C.D. Programa genes: estatística experimental e matrizes. Viçosa: UFV, 2006. 285p. 
DANNER, M.A.; SASSO, S.A.Z.; CITADIN, I.; AMBROSIO, R.; SACHET, M.R.; MAZARO, S.M. Variabilidade da qualidade de frutos de jabuticabeiras de diferentes sítios de ocorrência da região sudoeste do Paraná. In: CONGRESSO BRASILEIRO DE FRUTICULTURA, 20., 2008. Vitória. Anais... Vitória: Sociedade Brasileira de Fruticultura, 2008. CD-ROM

DEMATTÊ, M.E.S.P. Ornamental use of Brazilian Myrtaceae. Acta Horticulturae, Wageningen, n. 452, p.143-179, 1997.

EMBRAPA. Centro Nacional de Pesquisa de Solos. Sistema brasileiro de classificação de solos. Rio de Janeiro: EMBRAPA, 1999. 412 p.

IAPAR- Instituto Agronômico do Paraná. Cartas climáticas do Paraná: versão 2.0. Londrina: IAPAR, 2003. CD-ROM

INPE - Instituto Nacional de Pesquisas Espaciais. SPRING, versão 4.3.3. Disponível em: <http: \ www.inpe.br> Acesso em: 20 jun. 2008.

IPARDES- Instituto Paranaense de Desenvolvimento Econômico e Social. Mapas: Divisão PolíticoAdministrativa do Paraná - 2002. Disponível em: $<$ http://www.ipardes.gov.br/pdf/mapas/base_fisica/ divisao_politico_administrativa_2002.pdf $>$. A Acesso em: 22 nov. $200 \overline{8}$.

LARACH, J.O.I.; CARDOSO, A.; CARVALHO, A. P. et al. Levantamento de reconhecimento dos solos do Estado do Paraná. Curitiba: EMBRAPA SNLCS/SUDESUL/IAPAR, 1984. v.1, 414p. (Boletim Técnico, 57).

LORENZI, H. Árvores brasileiras: manual de identificação e cultivo de plantas arbóreas nativas do Brasil. 4. ed. Nova Odessa: Instituto Plantarum, 2002. v.1, 368p.
LORENZINI, A.R.; BOFF, M.I.C.; RECH, T.D.; BOFF, P. Fitogeografia da goiabeira serrana no Planalto Serrano Catarinense. Agropecuária Catarinense, Florianópolis, v.20, n.2, p.86-89, 2007.

MATTOS, J.L.R. Fruteiras nativas do Brasil: jaboticabeiras. Porto Alegre: Nobel, 1983. 92 p.

MESQUITA, M.A.M.; NAVES, R.V.; SOUZA, E.R.B.; BERNARDES, T.G.;SILVA, L.B. Caracterização de ambientes com alta ocorrência natural de araticum (Annona crassiflora Mart.) no Estado de Goiás. Revista Brasileira de Fruticultura, Jaboticabal, v.29, n.1, p.15-19, 2007.

NASCIMENTO, W.M.O.; CARVALHO, J.E.U.; MÜLLER, C.H. Ocorrência e distribuição geográfica de bacurizeiro. Revista Brasileira de Fruticultura, Jaboticabal, v.29, n.3, p.657-660, 2007.

PARANÁ. Decreto n 387, de 02 de março de 1999. Institui o Sistema de Manutenção, Recuperação e Proteção da Reserva Florestal Legal e Áreas de Preservação Permanente e dá outras providências. Disponível em: <http://www.pr.gov.br/ meioambiente/iap $>$ Acesso em: 25 set. 2008.

ROMAGNOLO, M.B.; SOUZA, M.C. O gên ero Eugenia L. (Myrtaceae) na planície alagável do Alto Rio Paraná, Estados de Mato Grosso do Sul e Paraná, Brasil. Acta Botanica Brasilica, São Paulo, v.20, n.3, p.529-548, 2006.

TEIXEIRA, L.N.; STRINGHETA, P.C.; OLIVEIRA, F.A. Comparação de métodos para quantificação de antocianinas. Ceres, Viçosa, MG, v.55, p.297-304, 2008 .

VALIO, I.F.M.; FERREIRA, Z.L. Germination of seeds of Myrciaria cauliflora (Mart.) Berg. (Myrtaceae). Revista Brasileira de Fisiologia Vegetal, Lavras, v.4, n.2, p.95-98, 1992. 